\title{
Novíssimas guerras, novíssimas pazes. Desafios conceptuais e políticos
}

Newest wars, newest peaces. Conceptual and political challenges

Les guerres les plus nouvelles, les paix les plus nouvelles. Défis conceptuels et politiques

\section{Tatiana Moura}

\section{OpenEdition}

\section{Journals}

\section{Edição electrónica}

URL: http://journals.openedition.org/rccs/1020

DOI: $10.4000 /$ rccs. 1020

ISSN: 2182-7435

\section{Editora}

Centro de Estudos Sociais da Universidade de Coimbra

Edição impressa

Data de publição: 1 Junho 2005

Paginação: 77-96

ISSN: 0254-1106

\section{Refêrencia eletrónica}

Tatiana Moura, "Novíssimas guerras, novíssimas pazes. Desafios conceptuais e políticos », Revista

Crítica de Ciências Sociais [Online], 71 | 2005, colocado online no dia 01 outubro 2012, criado a 19 abril 2019. URL : http://journals.openedition.org/rccs/1020 ; DOI : 10.4000/rccs.1020 


\section{Novíssimas guerras, novíssimas pazes. Desafios conceptuais e políticos}

Este texto pretende dar conta da emergência de um novo tipo de violência armada organizada (novíssimas guerras), que ocorre a uma escala cada vez mais micro mas se manifesta, tal como as novas guerras, a nível global. São duas as finalidades desta conceptualização: por um lado, tornar visíveis e "reais" contextos que têm sido considerados marginais, e que podem constituir o prelúdio de uma conflitualidade (ainda) mais disseminada no futuro; por outro lado, lançar o desafio de pensar e encontrar novos caminhos que respondam às inseguranças provocadas por este tipo de novíssima guerra.

\section{Introdução}

Este texto pretende dar conta da emergência de um novo tipo de conflitualidade violenta - a que chamo "novíssimas guerras" - com características, actores e estratégias específicos, que se manifesta em micro-espaços urbanos de países que vivem oficialmente em paz. Um dos exemplos deste novo tipo de conflitualidade é o Brasil e, em particular, a cidade do Rio de Janeiro. O país não vive um conflito armado ou uma guerra considerada tradicional, mas apresenta índices de violência directa ou de mortalidade provocada por armas de fogo muitas vezes superiores a regiões que são devastadas por conflitos armados declarados.

Os factores que provocam estas novas manifestações de violência são comuns a outros países da região e do mundo. No entanto, a complexidade que os caracteriza faz com que seja difícil definir teoricamente estes novíssimos tipos de conflitos, que têm características das definições de crime organizado, por um lado, e das chamadas novas guerras características dos anos 90 , por outro.

A finalidade desta conceptualização é dupla: por um lado, tornar visíveis contextos que têm sido considerados marginais mas que, não obstante, podem constituir o prelúdio de uma conflitualidade ainda mais disseminada no futuro; por outro lado, lançar o desafio de pensar e encontrar novos 
mecanismos que respondam às inseguranças provocadas por estas novíssimas guerras, analisando formas alternativas e não violentas de prevenção e de transformação destes conflitos - novíssimas pazes.

As propostas de análise de conceitos e de práticas de segurança avançadas pela crítica feminista das Relações Internacionais, que denunciam a manifestação de violências e de inseguranças a várias escalas, constituem, na minha opinião, um enorme contributo para as tentativas de definição e de reconhecimento de contextos pouco nítidos, onde a (micro)guerra parece diluir-se em cenários de aparente (macro)paz. Neste sentido, opto, neste texto, por me concentrar no protagonismo das mulheres em algumas das reacções e estratégias de prevenção de violência em cenários de novíssimas guerras.

\section{A nova geografia das guerras}

As décadas de 80 e 90 ficaram marcadas por profundas alterações nas referências de análise da conflitualidade internacional. As chamadas "novas guerras”, que ocorrem com maior incidência em Estados colapsados ${ }^{1}$, vêm contrastar com um tipo de conflitualidade de matriz vestefaliana, que correspondeu sobretudo à construção do Estado moderno, territorial, centralizado e hierarquicamente ordenado. Mary Kaldor (1999) foi pioneira na definição e análise deste novo tipo de conflitos, defendendo que estas novas guerras correspondem a um novo tipo de violência organizada que é diferente porque faz com que não se vejam as diferenças entre guerra (geralmente definida como violência entre Estados ou grupos organizados por motivos políticos), crime organizado (violência conduzida por grupos de organização privada, com objectivos privados, normalmente o lucro financeiro) e violações maciças de direitos humanos (geralmente por parte de Estados ou por grupos politicamente organizados contra indivíduos). Estas novas guerras, também apelidadas de "conflitos de baixa intensidade", guerras privatizadas ou guerras informais, têm características substancialmente distintas das guerras "tradicionais". De facto, nestas novas guerras não é fácil estabelecer na prática a distinção entre o privado e o público, o

\footnotetext{
${ }^{1}$ George Sorensen utiliza o conceito de "Estados frágeis" para descrever um conjunto de Estados com instituições e processos económicos e políticos enfraquecidos, reservando o termo "Estado falhado" para casos em que essa fragilidade se intensifica (apud Spanger, 2000: 3). Robert H. Jackson (1998) utiliza a expressão "Estados falhados" para caracterizar Estados que são reconhecidos internacionalmente como territórios soberanos, mas são, no entanto, incapazes de garantir as condições internas de paz, ordem e boa governação tradicionalmente associadas à independência política. Nos Estados considerados "falhados", é reconhecido um governo oficial, enquanto os Estados considerados "colapsados" se caracterizam por uma total ausência de governo legítimo. Contudo, a diferença entre eles coloca-se em termos de amplitude ou de escala (ASC et al., 2003).
} 
estatal e o não estatal, o informal e o formal, o que se faz por motivos económicos ou políticos. Na opinião de Mark Duffield (2001), mais do que expressões de ruptura ou de caos, as novas guerras podem ser entendidas como uma forma de guerra em rede (network war) não territorial que actua através dos Estados e à volta deles, ou seja, guerras que se baseiam em redes cada vez mais privatizadas de actores estatais e não estatais que actuam para além das competências convencionais de governos definidos territorialmente. Trata-se de guerras que atenuam as distinções entre pessoas, exércitos e governos (Duffield, 2001: 13-14) e que resultam de um esbatimento de fronteiras (entre o interno e o externo, por exemplo) que anteriormente se consideravam rígidas e bem definidas, ao mesmo tempo que reforçam esse esbatimento.

Ao contrário das guerras tradicionais, que tinham a esfera pública como cenário da violência, nas novas guerras a sociedade civil é simultaneamente o palco e o alvo da violência organizada, que ocorre na esfera privada, privatizando a violência, os seus espaços ou territórios de actuação, os seus actores e as suas vítimas. Tornou-se quase um lugar comum lembrar que em inícios do século XX a proporção entre baixas militares e civis nas guerras era de 8 para 1. Actualmente, essa proporção inverteu-se e a proporção entre as baixas militares e civis é de 1 para 8. Trata-se, portanto, de guerras declaradas contra a dimensão privada das sociedades, silenciando a morte de milhares de pessoas. Apesar de penalizadas ética e juridicamente, as atrocidades deliberadas contra a população não combatente ou a destruição de monumentos históricos não só persistem como adquirem um alcance mais intensamente deliberado nas novas guerras. Ou seja, o que era considerado como efeito secundário indesejável e ilegítimo das velhas guerras tornou-se um elemento essencial da forma de luta das novas guerras, recusando limites normativos (Kaldor, 1999).

As unidades de combate envolvidas nestas novas guerras (públicas e privadas), que dificilmente se distinguem da população civil e cada vez mais se caracterizam pela utilização de crianças-soldado, o uso alargado de armas ligeiras (que são mais fáceis de transportar, mais precisas e podem ser utilizadas por soldados sem formação especial), o recurso a novas tecnologias (como telemóveis e internet), os novos métodos utilizados para obtenção de controlo político, ${ }^{2}$ a criação e manutenção de um clima de ódio, medo e insegurança constituem algumas das principais características que distinguem este tipo de violência organizada das velhas guerras.

\footnotetext{
2 Como refere Mary Kaldor "a ideologia não é importante, e os novos guerreiros estabelecem o controlo político mediante a adesão a um emblema, mais do que a uma ideia” (1999: 129).
} 
As novas características da violência fazem, de facto, com que as diferenças entre as zonas de combate e as zonas de paz aparente não sejam tão claras como em épocas anteriores e que, neste novo cenário, "assim como é difícil distinguir entre o político e o económico, o público e o privado, o militar e o civil, [seja] também cada vez mais difícil distinguir entre a guerra e a paz" (Kaldor, 2001: 143).

No entanto, estes espaços ou zonas de indefinição não são recentes. Ao longo do século XX (em particular na segunda metade do século), as baixas de "guerra" não ocorreram apenas durante conflitos armados tidos como tradicionais, em guerras com fronteiras perfeitamente nítidas. Como lembra Mary Kaldor (2001), ao mesmo tempo que se viviam guerras assumidas enquanto tal, em particular na Europa, eclodiram conflitos nos quais morreram mais pessoas do que na II Guerra Mundial. No entanto, como esses conflitos não se ajustavam a uma determinada concepção de guerra, não foram tidos em consideração, foram vistos como periféricos, marginais, "conflitos de baixa intensidade", guerras irregulares e informais e, portanto, abafados pela importância de conflitos considerados centrais.

Kalyvas (2001) analisa esta linha de argumentação que pretende distinguir entre "velhas guerras civis" e "novas guerras civis" do pós-Guerra Fria e critica a leitura dicotómica que ela sustenta. A maioria das distinções entre velhas e novas guerras civis defende que as "novas guerras civis têm características criminosas, são despolitizadas, privadas e predatórias, enquanto as velhas guerras civis são consideradas ideológicas, políticas, colectivas e mesmo nobres" (Kalyvas, 2001: 100). Esta distinção faz-se em torno de três dimensões: causas e motivações, apoio popular e violência. Em primeiro lugar, defende-se que as velhas guerras civis eram motivadas por ideologias de mudança social, bem definidas, claramente articuladas, universalistas, enquanto as novas guerras civis tendem a ser motivadas por preocupações que vão pouco além do mero ganho privado, recorrendo à distinção entre ganância (greed) e ressentimento (grievance) proposta, entre outros, por Collier e Hoeffler (2000). Kalyvas assinala a este propósito o argumento utilizado por Enzensberger, que refere a ausência de objectivos das novas guerras civis, ao afirmar que "o que confere às guerras civis de hoje um carácter novo e aterrorizador é o facto de serem travadas sem que nenhum dos lados defina os seus motivos, de serem guerras sobre coisa nenbuma" (apud Kalyvas, 2001: 103). Em sentido oposto, Duffield defende que "as novas guerras são organicamente associadas a um processo de transformação social: a emergência de novas formas de autoridade e de zonas de regulação alternativa" (2001: 14). Uma segunda distinção entre velhas e novas guerras civis realça que as primeiras nasciam supostamente da acumu- 
lação de ressentimentos populares, pressupondo-se, portanto, que tinham na sua base um apoio popular considerável, enquanto nas novas guerras civis os actores políticos parecem não ter tal apoio. No entanto, as lealdades individuais nas velhas guerras civis, tal como nas novas guerras civis, são mais influenciadas por divergências locais, em constante mudança, do que por discursos impessoais que utilizam a linguagem das clivagens nacionais, dos ressentimentos colectivos (Kalyvas, 2001: 109-111). Finalmente, a terceira dimensão em torno da qual parece basear-se a distinção entre velhas e novas guerras civis é a violência: violência controlada das velhas guerras civis versus violência gratuita das novas guerras.

Stathis Kalyvas mostra, porém, que a ideia de que as guerras civis são gratuitamente cruéis é anterior à emergência das chamadas novas guerras civis: "a violência dos mais fortes pode expressar-se através do uso de explosivos ou bombas de napalm. Mas estas armas não são diferentes das granadas de mão atiradas do cimo de telhados; de facto, as granadas farão mais vítimas inocentes" (Kalyvas, 2001: 115). Por outro lado, a falta de sentido da violência das novas guerras civis não é tão gratuita como aparenta: é estratégica. Assim, por exemplo, as atrocidades cometidas na Serra Leoa (1998-1999), na Bósnia (1992) ou no Congo (1997-2000) foram cuidadosamente planeadas e centralizadas e resultaram de uma estratégia orquestrada para aterrorizar as vítimas sendo apoiadas e controladas a partir do exterior. Em suma, há muito de construído nesta visão que opõe velhas a novas guerras civis. Pode dizer-se que o destaque dado às notas da despolitização e da criminalização das guerras civis mais recentes não é tanto expressão de uma novidade empírica como resultado da falta de categorias conceptuais adequadas, isto é, de se tratar de conflitos que não se ajustam a uma determinada concepção de guerra.

Estas formas de violência, com actores, técnicas e estratégias "atípicos", que não se ajustavam a uma determinada concepção de guerra vieram a ser, já nos nossos dias, académica e politicamente aceites como "guerras a sério", reconhecidas pela comunidade internacional enquanto tal. Temos vindo a assistir, portanto, a uma tendência para a materialização de uma nova geografia da violência organizada, a uma escala cada vez mais micro, com guerras locais que têm impacto à escala global.

\section{Novíssimas guerras à margem das novas guerras?}

Essa dinâmica de disseminação física da violência armada, a uma escala cada vez mais micro, está bem patente sobretudo nas zonas de indefinição, onde a guerra se confunde com a paz. Em sociedades que vivem processos de reconstrução pós-conflito dominados por preocupações de curto prazo e por um quadro de referências políticas, económicas e sociais de recorte 
neoliberal, facilmente se opera uma transferência da violência militar anterior para uma violência social disseminada, em que o arsenal de cultura de violência acumulada ao longo de décadas jorra em violência armada organizada. Veja-se, por exemplo, o caso de El Salvador, que entre 1990 e 1995 , após a assinatura dos acordos de paz, testemunhou um aumento da taxa de homicídios de 79 para 139 homicídios por cada 100 mil habitantes. Como defende Briceño-León, começaram a registar-se mais mortes na calma da paz do que nas tormentas da guerra (2002: 13). Por outro lado, e mesmo fora destes contextos identificados de reconstrução pós-bélica, registam-se situações de hiper-concentração territorial de violência armada (organizada) em contextos mais vastos de paz institucionalizada e formal. Estarão a emergir "novíssimas guerras" nas entrelinhas, nas brechas das novas guerras? As guerras irregulares e informais da segunda metade do século XX foram o prelúdio das novas guerras. Estará a emergir agora um novo tipo de violência que, por não corresponder ainda a nenhuma concepção de guerra, é marginalizado e não é tido como relevante?

A minha hipótese é que, neste novo tipo de conflitualidade, se cruzam duas dinâmicas de sentido oposto: de um lado, uma dinâmica "descendente" traduzida numa "descida" da violência armada (organizada) cada vez mais ao terreno do doméstico; do outro, uma dinâmica "ascendente" que se concretiza na intensificação de formas ditas "tradicionais" de violência suburbana. A singularidade desta forma de violência distingue-a das chamadas "novas guerras", ou de conflitos internos que têm lugar em Estados colapsados. Apesar das semelhanças quanto aos objectivos (controlo do território e de recursos estratégicos), a escala é diferente. Não se trata de conflitos territoriais ou por recursos que opõem grupos beligerantes que disputam ao Estado o monopólio do uso da força, mas sim de concentrações de grande intensidade de violência em territórios muito limitados, ou micro-territórios (bairros, comunidades urbanas, zonas suburbanas), dentro de um contexto nacional de paz aparente, institucionalizada e formal. São conflitos que têm uma vocação de poder, mas de um poder paralelo, que não pretende substituir-se ao poder estatal. No entanto, na opinião de Manwaring (2005), as estratégias de actuação desta nova forma de conflitualidade podem pressupor o controlo de micro-territórios de países ou de sub-regiões dentro de um país, criando enclaves que são, essencialmente, para-Estados. E ainda que as actividades e objectivos daquilo a este autor que chama "actores não estatais de uma guerra não estatal e não convencional” não sejam alcançados, este tipo de conflitualidade contribui para um processo degenerativo de fragilização ou fracasso estatal e para a instabilidade regional (ibid:: 12). 
A origem e a expansão da violência e crime urbanos - que tendem a localizar-se nas zonas mais degradadas das grandes cidades - foram associadas pela sociologia urbana a processos de marginalização e exclusão social e a fenómenos de segregação espacial urbana. No entanto, é importante reconhecer que, para além do aumento dos excluídos urbanos e do seu afastamento dos padrões de vida dos incluídos, existe uma nítida separação entre dois mundos sociais, apesar da sua proximidade física. A linha que os separa determina os que têm e os que não têm. Como defende Alba Zaluar, de um lado temos o asfalto, as classes prósperas e a democracia; e do outro, temos o morro e os pobres condenados à eterna falta de direitos cívicos, políticos e sociais (1994: 49). De facto, as megacidades representam "a face metropolitana da exclusão social” (Dupas, 1999: 48), por serem depositárias de muitos segmentos excluídos da população.

Assistimos no entanto, desde há uns anos, a uma reconfiguração dos próprios conflitos urbanos. As revoltas pontuais de cidadania, com objectivos limitados, testemunhadas pelas grandes cidades dos países ricos (Young, 1999), transformam-se em guerras civis, permanente e militarmente organizadas, em espaços urbanos com maiores desigualdades sociais.

Este novo tipo de conflitualidade distingue-se da simples criminalidade interna de larga escala. A fronteira cada vez menos nítida entre a esfera interna e internacional em cenários de novíssimas guerras faz com que a definição ou caracterização desta nova conflitualidade dependa das "lentes" ou dos filtros com que analisamos estes contextos. Se nos centrarmos única e exclusivamente na dimensão interna, pouco mais veremos do que um cenário de criminalidade hiper-concentrada, sem objectivos políticos. Mas se compreendermos os impactos destes fenómenos locais no contexto internacional, veremos que estamos perante a emergência de conflitos de tipo novo, disseminados à escala global. Ao chamar "novíssimas guerras" a este tipo de conflito violento, pretendo realçar esta diferença importante.

A América Latina é hoje porventura um dos palcos mais expressivos deste "novo" tipo de violência. Ele emergiu nos anos 80 e 90 e resulta da combinação de vários factores: a persistência de elevados níveis de desigualdade social, as taxas baixas ou negativas de crescimento económico, o elevado índice de desemprego e de emprego precário, o rápido crescimento das grandes cidades e das áreas metropolitanas, a homogeneização e inflação das expectativas dos jovens que nascem nas comunidades mais pobres, a ausência ou fragilidade de infra-estruturas urbanas básicas, de serviços sociais básicos e de organizações da sociedade civil em bairros mais pobres, a disponibilidade crescente de armas ligeiras e drogas, a presença crescente e cada vez mais forte do crime organizado, a cultura da violência mantida e 
perpetuada pelo crime organizado e pelos meios de comunicação e, finalmente, o baixo nível de eficácia da polícia e de outras instituições do sistema de justiça criminal. Briceño-León (2002) sublinha que em finais do século XX a violência foi a primeira causa de morte na América Latina entre pessoas com idades compreendidas entre os 15 e os 44 anos.

A nova tipologia da violência na América Latina resulta da agudização das violências estruturais sentidas ao longo das últimas décadas, é legitimada pela cultura, tem novas características e propaga-se em novos espaços. Peter Gizewski e Thomas Homer-Dixon (1995) defendem que o crescimento urbano rápido, em interacção com os factores acima referidos, constitui uma das principais causas destes novos tipos de violências, directa e estrutural. Este novo tipo de violência atinge, em particular, a população mais pobre dos grandes centros urbanos. No entanto, a pobreza não é o factor explicativo deste aumento da violência, uma vez que os países mais pobres da América Latina, como o Peru ou a Bolívia, não contam com as taxas de homicídio mais elevadas. O mesmo sucede no interior dos países. No Brasil, por exemplo, os maiores índices de violência não se registam nas zonas mais pobres do Nordeste do país, mas sim nos estados mais cosmopolitas do Rio de Janeiro ou de São Paulo (Zaluar, Noroña e Albuquerque, 1994). É o empobrecimento e a desigualdade, e não a pobreza, que origina a actual violência urbana.

Nestes novos cenários, as mulheres são um dos colectivos mais afectados. A cultura de violência que legitima o uso das armas de fogo e as mortes daí resultantes e a estrutura (a violência estrutural) que a sustenta, vitimam em particular mulheres. São as mais pobres dos pobres, vítimas das desigualdades sociais, as mais afectadas pelo desemprego e pelo emprego precário, pela desigualdade nas oportunidades de educação, pelas relações de poder desiguais que as colocam numa situação de vulnerabilidade perante a violência, tanto na esfera privada (como se comprova pelos elevados índices de violência doméstica que se registam na América Latina) como na esfera pública (de que são exemplo os casos de feminicídios na Ciudad Juarez, no México, ou na cidade da Guatemala). Esta violência conta, agora, com as armas de fogo como instrumento privilegiado.

\section{O feminismo, na confluência da micro-guerra e da macro-paz}

A conceptualização deste novo tipo de violência organizada que tenho vindo a referir, que ocorre a uma escala cada vez mais micro mas se manifesta, tal como as novas guerras, a nível global, tem duas finalidades: por um lado, tornar visíveis e "reais" contextos que têm sido considerados marginais, e que podem (tal como as novas guerras) constituir o prelúdio de uma confli- 
tualidade (ainda) mais disseminada no futuro; por outro lado, lançar o desafio de pensar e encontrar novos caminhos que respondam às inseguranças provocadas por este tipo de novíssima guerra.

O final da Guerra Fria e a emergência ou maior visibilidade de riscos - como os novos tipos de conflitualidade que ocorrem maioritariamente dentro de Estados, e não entre Estados - em parte abafados pela tradição realista de insegurança, e a emergência do terceiro debate em Relações Internacionais, entre positivismo e pós-positivismo, vieram reforçar a necessidade de abertura da agenda limitada e estatocêntrica da segurança. Aos estudos tradicionais sobre segurança começaram a contrapor-se os estudos críticos sobre segurança, que consideravam não ser possível incluir questões cruciais para o entendimento da segurança a partir de uma epistemologia positivistaracionalista ou de uma ontologia baseada em actores racionais instrumentalizados num mundo estatocêntrico (Tickner, 2001: 45).

$\mathrm{Na}$ década de 70, Olof Palme tinha já proposto uma nova abordagem ao conceito de segurança, no Relatório da Comissão Independente sobre Questões de Desarmamento e Segurança (conhecido por Relatório Palme): a segurança entendida como sobrevivência conjunta e não destruição mútua, entendida enquanto segurança comum, denunciando as contradições entre a segurança militar dos Estados e o bem-estar económico dos seus cidadãos e cidadãs e salientando a noção de interdependência global. No mesmo sentido, o relatório da Comissão sobre a Governação Global defende que as fronteiras dos Estados têm vindo a tornar-se cada vez mais ilusórias e que a insegurança individual tem vindo a aumentar, em resultado de novos riscos como a destruição ambiental ou a violação de direitos humanos (The Commission on Global Governance, 1995: 79). Estas inseguranças e a necessidade de novas soluções, ignoradas pela abordagem estatocêntrica, que resultam de aspectos essenciais de interdependência ecológica e económica, entre outros, conduziram ao aparecimento de novos conceitos, como o de segurança bumana (ibid.: 80). Este novo tipo de segurança, que tem como preocupação central a dignidade humana, foi popularizado pelo Relatório sobre Desenvolvimento Humano do Programa das Nações Unidas para o Desenvolvimento (PNUD) de 1994. Este Relatório considera a (in)segurança humana como a soma de um conjunto de (in)seguranças: económica, alimentar, na saúde, ambiental, pessoal, colectiva e política.

As propostas de segurança comum e de segurança humana (PNUD, 1994 e The Commission on Global Governance, 1995) constituíram apenas um passo na transformação pretendida pelas análises feministas das Relações Internacionais, uma vez que os conceitos que propõem situam-se ainda numa lógica tendencialmente macro-social e não questionam as relações sociais 
de poder que geram inseguranças. Do mesmo modo, são também macro as tentativas de resposta para inseguranças que, nessa visão dominante, se colocam apenas ao nível nacional ou internacional.

Por isso mesmo, as críticas feministas às Relações Internacionais começaram a questionar quem ou o quê deve ser o objecto de segurança, que níveis de análise se favorecem e quem ou o quê constitui uma ameaça à segurança. O nível de análise micro-social introduzido pela crítica feminista das Relações Internacionais e pela perspectiva feminista de paz veio reforçar a visibilidade da ineficácia deste modelo de segurança tradicional, que vê no poder militar o instrumento privilegiado para manter a ordem mundial hierárquica num sistema exclusivamente estatocêntrico. Para o feminismo, ao invés, o paradigma de segurança estatocêntrico não só não pressupõe a eliminação da violência como a eterniza, já que a sua "hiperconcentração na segurança entre Estados põe entre parênteses a insegurança inter-pessoal que se reforça e perpetua de acordo com padrões culturais enraizados" (Pureza e Moura, 2004). Segurança nacional e insegurança individual são duas faces do mesmo entendimento tradicional da segurança, que faz equivaler segurança a cidadania. Neste, as únicas ameaças reais são as de carácter político-militar; e, por outro lado, a militarização da sociedade, enquanto contra-face dessa visão da insegurança, é afinal uma manifestação visível do patriarcado, enquanto modo de governação e modelo de dominação. Esta proposta tradicional concebe, portanto, a segurança de forma fragmentada, com claras fronteiras entre a desordem internacional e a ordem nacional, uma vez que pressupõe que, num sistema internacional anárquico, a única forma de um Estado garantir a sua segurança é maximizando o seu poder e assegurando a sua não-dependência (Tickner, 1992: 27-32).

Numa perspectiva feminista, é ainda necessária a ruptura com o status quo dominante, substituindo o paradigma tradicional de segurança por uma definição de segurança de proximidade, que tenha como preocupação central a dignidade humana e que marque uma clara ruptura com o corpo conceptual característico da Guerra Fria, tanto relativamente à definição da ameaça como à identificação do objecto da segurança e à gestão dos meios utilizados para combater a ameaça, reduzindo ou eliminando, deste modo, relações de poder hierárquicas. As análises feministas das Relações Internacionais desafiam a dicotomia público/privado e denunciam as inseguranças que daí derivam, ocultadas pelo paradigma estatocêntrico da segurança nacional (Pettman, 1996: 106), e propõem um conceito de segurança multidimensional que responda às várias esferas de manifestação das violências. A violência que ocorre na esfera considerada pública não pode 
dissociar-se da violência que ocorre na esfera privada, uma vez que corresponde ao mesmo fenómeno que se manifesta em diferentes escalas. Neste sentido, a redefinição de segurança tem que ter em conta as várias dimensões e níveis de insegurança (ou manifestações de violência): o pessoal não pode estar separado do político e do internacional - a (in)segurança pessoal está relacionada com a (in)segurança internacional. Em finais dos anos 60, algumas feministas começaram a alertar para o facto de a esfera pessoal ser política, ou seja, a defender que a subordinação das mulheres na esfera chamada privada está directamente relacionada com a subordinação das mulheres na esfera pública, e vice-versa. A dicotomia público/privado constrói-se à custa da desvalorização e silenciamento de tudo o que ocorre na esfera privada. Por isto mesmo a reclamação do pessoal enquanto algo que é também político surge enquanto tentativa de subverter as relações de poder dominantes.

\section{Novíssimas guerras, novíssimas pazes: o caso do Rio de Janeiro}

O Brasil é um exemplo claro de um país que vive este novo tipo de conflitualidade. Trata-se de um país que não está envolvido em nenhuma guerra oficial mas que, não obstante, apresenta em algumas regiões uma das taxas mais elevadas de homicídio provocadas por armas ligeiras do mundo. Com o final da ditadura militar mantida pelas Forças Armadas, que assumiram o controlo do país em 1964, o Brasil não se converteu numa sociedade mais pacífica. A agudização da violência urbana de tipo directo, quantificável actualmente pelas estatísticas, resulta de violências estruturais e culturais que se enraizaram no país. Na opinião de Angelina Peralva (apud Lealdino, 2000: 91-92), a lenta transição para a democracia teve como consequência a debilidade do Estado e a sua incapacidade para controlar a violência, ainda que a segurança continue nas mãos da polícia militar, herdada da ditadura. A combinação de factores como o rápido crescimento urbano e a falta de infra-estruturas de habitação (que conduziram ao aumento de bairros ou comunidades pobres nas periferias das grandes cidades a partir de finais dos anos 60); a elevada desigualdade na distribuição de riqueza; o crescimento económico lento; a dependência de empréstimos internacionais; os baixos níveis de vida da população; a disponibilidade crescente de armas de fogo (o Brasil é o segundo maior exportador de armas ligeiras no continente americano e o quinto exportador do mundo [Bandeira, 2003]); a emergência do narcotráfico e de grupos armados organizados (em particular no Rio de Janeiro); a incapacidade ou ausência de resposta por parte do Estado; a memória, a cultura e a prática da violência mantida e perpetuada pela polícia e por grupos de segurança privada; estes são factores que 
estão na raiz da explosão da violência directa urbana que teve início em finais dos anos 80 e se mantém até hoje, em particular na cidade do Rio de Janeiro. Tal como em sociedades que vivem um processo de reconstrução pós-bélica, as memórias da violência e a debilidade estatal contribuem para a emergência de um novo tipo de conflitualidade.

O Rio de Janeiro conta hoje com uma das taxas de homicídio mais elevadas do mundo. Entre 1991 e 2002, cerca de 90 mil pessoas foram mortas com armas de fogo. A população brasileira constitui $2,8 \%$ da população mundial, mas no país registaram-se, ao longo dos anos 90, entre $9 \%$ e $13 \%$ das mortes provocadas por armas de fogo registadas no mundo. A história e o rosto deste novo tipo de violência estão directamente relacionados com a emergência do narcotráfico, do tráfico de armas e dos grupos que os controlam. Apesar de o tráfico de droga no Rio de Janeiro não ser recente (datando de inícios do século XX), somente em finais dos anos 70 e início dos anos 80 , com a chegada de enormes quantidades de cocaína à cidade, ela passou a ser um ponto de passagem importante para a exportação de cocaína para os E.U.A., Europa e África do Sul (Dowdney, 2003: 25). As estatísticas demonstram que a violência armada directa, espelhada nas taxas de mortalidade, começou a aumentar justamente depois de meados dos anos 70: em 1980 registaram-se 1807 homicídios no Rio de Janeiro (ou seja, 35,5 homicídios por cada 100 mil habitantes); mas em 1989 este número aumentou para 3516, ou seja, 64,9 homicídios por cada 100 mil habitantes. Esta taxa manteve-se até ao ano 2000 (Dowdney, 2003: 92).

Como em toda a América Latina, as causas deste aumento têm uma relação directa com a disseminação e utilização de armas de fogo. No Brasil, entre 80 e $90 \%$ do número total de homicídios são provocados por armas de fogo. Em 1960, foram apreendidas pela polícia no estado do Rio de Janeiro 841 armas, mas em 1999 este número aumentou para 11633 armas ilegais, mais letais e tecnologicamente mais avançadas. Este aumento da apreensão de armas, a partir dos finais dos anos 80, "acompanha a emergência das facções de droga, a sua fragmentação, militarização e as disputas armadas pelos territórios, e também o aumento dos confrontos com a polícia” (Dowdney, 2003: 93). No Rio de Janeiro, existem três facções de droga, ou grupos armados que disputam o controlo territorial das comunidades pobres (favelas) com objectivos económicos de controlo do narcotráfico: Terceiro Comando, Comando Vermelho e Amigos dos Amigos. Seguindo os padrões e características já mencionados sobre a nova violência na América Latina, podemos constatar que, no Rio de Janeiro, uma grande metrópole, a violência é específica de alguns bairros e não afecta de igual modo a população. Como afirma Luke Dowdney (2003: 94), "algumas zonas têm 
um número de mortes semelhante a algumas cidades da Europa e dos E.U.A., com menos de 10 homicídios por 100 mil habitantes, e outras zonas têm índices semelhantes a áreas em conflito armado ou em guerra (com índices entre os 100 e os 501 homicídios por cada 100 mil habitantes)". Apesar das taxas de mortalidade provocada por armas de fogo, comparáveis às perdas sofridas e provocadas em muitas guerras contemporâneas, a cidade e o país não estão a viver uma "guerra" (Dowdney, 2003: 13). No entanto, as manifestações do comércio ilegal de droga no Rio de Janeiro supõem níveis de violência armada, taxas de mortalidade provocadas por armas de fogo, uma organização paramilitar, a territorialização geográfica, a dominação política das comunidades pobres e a participação das autoridades do Estado que atingem níveis que não se registam em nenhum outro lugar do mundo (ibid.: 239).

Os conflitos armados que ocorrem no Rio de Janeiro são protagonizados pelas facções de droga, que apresentam características e modos de actuação semelhantes. São estruturadas hierarquicamente (enquanto unidade armada organizada) no âmbito local. Têm objectivos económicos e não se distinguem ideologicamente (apesar de os grupos terem códigos de comportamento, estruturas organizativas e noções de justiça distintos, têm em comum o objectivo económico de venda ilegal de droga na cidade, bem como estratégias semelhantes de dominação da comunidade e do seu território como base do poder). Enquanto grupo armado, são financeiramente auto-suficientes pelo seu próprio objectivo e não dependem de outros crimes para se armarem. Apesar de não existirem diferenças ideológicas entre elas, as facções demonizam os seus rivais, doutrinando os membros da comunidade, e em particular os jovens, numa cultura de ódio e de medo ao "outro" (ou seja, das facções rivais e das comunidades dominadas por elas). As facções são territoriais, definem-se geograficamente através do domínio das favelas onde estão os seus pontos de venda. Controlam as comunidades de favela, num domínio imposto através de regras e castigos clandestinos. Constituem uma presença armada constante nas comunidades dominadas e possuem armamento de guerra. Recorrem a armas de fogo para perpetuar a violência, tendo como resultado um maior número de mortes do que as registadas em algumas áreas que vivem uma "nova guerra". As crianças são (à semelhança do que acontece nas novas guerras), utilizadas pelas facções nas disputas territoriais armadas, nos confrontos armados com facções rivais e com a polícia. Em síntese, as situações em que ocorrem "novíssimas guerras" vêm exacerbar exponencialmente o pluralismo jurídico tradicional (Santos, 1997), adicionando-lhe uma componente de violência armada organizada, com efeitos quer ad intra, quer ad extra, que passa a ser 
a base fundamental da existência de verdadeiros micro-estados dentro do Estado, delimitados pela ordem e pela lei geral que é definida pelas facções de droga.

Uma vez que o Estado não é o alvo deliberado dos ataques das facções de droga no Rio de Janeiro, não pode afirmar-se, à luz dos padrões conceptuais tradicionais, que a cidade ou o país vivam uma guerra. Apesar da organização paramilitar local, do objectivo de domínio territorial e político sobre espaços geográficos, do elevado número de combatentes armados (incluindo ex-militares) e da sua presença constante nas comunidades que dominam, das armas de utilização militar e dos índices de violência armada que matam muito mais do que 1000 civis e combatentes por ano, as facções do narcotráfico da cidade do Rio de Janeiro não se opõem nem têm interesse em assumir o lugar do Estado. São poderes simultâneos, e o Estado pode formalmente entrar e intervir em todos os espaços da cidade. E, apesar de terem uma organização interna, códigos de conduta e uma cadeia de comando, as facções não estão estruturadas como organizações militares, onde todos os membros têm um mesmo chefe independentemente da unidade local que representam (Dowdney, 2003: 193-195).

A proposta avançada por Dowdney para situar as disputas territoriais das facções de droga no Rio de Janeiro é a de uma situação intermédia entre crime organizado e guerra que ele designa por violência armada organizada. ${ }^{3}$

Ao analisarmos os rostos da nova conflitualidade que se manifesta com particular incidência no Rio de Janeiro, reparamos que os homens são desde logo as principais vítimas directas da violência armada. Por cada 24 homens mortos com armas de fogo no Brasil (com idade entre os 15 e os 29 anos), morre uma mulher (Amnistia Internacional, 2003). Sendo masculino, o rosto desta violência é também predominantemente jovem. A taxa de homicídios entre os jovens com idades compreendidas entre 15 e 29 anos foi de 239 por 100 mil habitantes, em 1999, registando-se um aumento do número de mortes entre os jovens com 10-14 anos (ou seja, há uma componente infantil crescente nesta faceta jovem da violência no Brasil, e em particular

\footnotetext{
3 "[...] é uma situação intermitente de conflito armado que resulta em mais de 1000 mortes de combatentes e civis num período de um ano, resultante da acção de grupos armados não estatais, organizados ou semi-organizados, sem motivação política, religiosa, étnica ou ideológica, territorialmente definidos e que têm um controlo efectivo sobre as comunidades que dominam, utilizando armas ligeiras e possuindo uma organização paramilitar a nível local, tendo em vista ganhos económicos ilegais. Utiliza para isso crianças e adolescentes como combatentes armados e eventualmente enfrenta o Estado recorrendo à violência armada quando o seu objectivo económico se encontra ameaçado, mas sem a intenção de substituir o governo do Estado ou de atacar o governo em busca de vantagens políticas ou territoriais" (Dowdney, 2003: 203).
} 
no Rio de Janeiro). O número de mortes de menores de 18 anos provocadas por armas de fogo no Estado do Rio de Janeiro é superior a algumas regiões do mundo que vivem uma guerra. Por outro lado, são também jovens e homens os principais agentes desta violência. Para isso concorre, a título principal, a mística da masculinidade (Fisas, 1998) e toda a simbologia das armas de fogo a ela associada e enraizada na cultura de violência que predomina na América Latina. O monopólio masculino do uso e posse de armas de fogo é, na realidade, uma expressão da socialização num tipo de masculinidade, violenta, de culturas locais e nacionais em que a utilização masculina de armas de fogo é a norma. Em tempos de guerra e em países "pacíficos" as armas fazem muitas vezes parte de um ritual de passagem da infância para a idade adulta dos rapazes, que são frequentemente socializados de forma a sentirem familiaridade e fascínio com e por armas (Connell, 1985). Estes elementos simbólicos vêm associar-se aos demais factores já referidos para caracterizar a singularidade destas novíssimas guerras.

Apesar de as principais vítimas e agentes da violência serem homens, há uma tendência de crescimento de mortes de mulheres provocadas por armas de fogo. Entre 1979 e 1981, a mortalidade feminina por homicídios no país era de 2 óbitos por cada 100 mil mulheres. Segundo o estudo "Mortalidade Feminina por Causas Externas: Brasil e Macro Regiões (1979 a 1999)", entre 1997 e 1999 esse número aumentou para 4 óbitos por 100 mil mulheres, sendo a arma de fogo o instrumento utilizado (Aguiar, 2004). Este mesmo estudo revela que as armas são responsáveis por $54 \%$ dos homicídios de mulheres com idades compreendidas entre os 20 e os 29 anos, e por $49,9 \%$ das mulheres com idades compreendidas entre os 40 e os 49 anos. De facto, e na opinião de Barbara Frey, relatora especial da ONU sobre a prevenção de violações de direitos humanos cometidas com armas ligeiras,

[...] apesar de as sociedades [...] justificarem frequentemente a posse de armas de fogo com a alegada necessidade de proteger mulheres vulneráveis, na realidade as mulheres enfrentam um perigo ainda maior de violência quando as suas famílias e comunidades estão armadas. (UN Doc. E/CN.4/Sub.2/2004/37)

Uma das contra-faces do rosto jovem e masculino da violência armada (organizada ou não) é, em grande medida, o protagonismo de mulheres ${ }^{4}$

\footnotetext{
${ }^{4}$ Opto, neste texto, por me concentrar exclusivamente em reacções às novíssimas guerras protagonizadas por mulheres. A minha escolha tem razões práticas - é esse rosto feminino das novíssimas pazes que constitui o meu presente objecto de investigação -, mas deriva também de
} 
nas respostas a ela. Na opinião de Luciana Phebo e Michel Robim (2004), "o medo, a insegurança, o ressentimento e as dificuldades financeiras fazem parte da herança deixada pelas mortes de jovens do sexo masculino”. No entanto, relembram, a mulher não é apenas vítima, é frequentemente protagonista da prevenção do uso de armas de fogo. De facto, a maioria das reacções organizadas de repúdio a esta novíssima guerra é protagonizada por mulheres. O seu papel é cada vez mais importante, em particular nas tentativas de diminuição da procura de armas de fogo, nos movimentos de sensibilização da opinião pública, enquanto grupo de pressão sobre o governo e, em particular no caso do Rio de Janeiro, um importante movimento de reacção à violência armada. Consciente do peso da simbologia, a ONG Viva Rio iniciou, no dia 13 de Maio de 2001 (Dia da Mãe, no Brasil), uma campanha de desarmamento intitulada "Arma Não! Ela ou Eu”. A organização actuou como veículo de facilitação e mobilização, tentando reunir, dar voz e expressão pública às mulheres de todos os sectores da sociedade brasileira numa luta conjunta pela redução da violência e pela entrega voluntária de armas. O fácil acesso e disseminação de armas de fogo na maioria das famílias como símbolo de protecção e de dominação é ainda uma prática comum. Num país com elevadas taxas de violência doméstica, a mensagem escolhida para esta campanha era que as armas não são sinónimo de segurança e, por isso, as mulheres uniam-se pelo desarmamento dos seus lares e do seu país. O que inicialmente poderia explicar-se como uma estratégia de sobrevivência (para a sua protecção e das suas famílias) rapidamente se une a uma tentativa de conquistar um espaço na esfera pública.

Para além desta mobilização ou campanha, ao longo dos anos têm emergido, no país, outras formas de reacção à violência protagonizadas por mulheres, como as Mães de Acari (que até aos dias de hoje procuram os seus filhos desaparecidos) ou o grupo Mães do Rio. Este último reúne mais de 300 mães com histórias semelhantes, que lutam pela punição dos auto-

opções epistemológicas. Com efeito, a minha proposta de construção e de análise das novíssimas estratégias de prevenção de violência e de paz é que estas conferem tacitamente às epistemologias feministas - de denúncia dos mecanismos de manutenção e reprodução de uma cultura da violência (o sistema patriarcal) e dos seus ícones (a posse e uso de armas de fogo) - um estatuto fundamental na sua fundamentação. Por outro lado, seja com raízes numa abordagem construtivista que sublinha a construção e imposição das identidades pelos papéis sociais a que estas mulheres ficam convocadas nestes contextos - seja através da aplicação do que poderia chamar-se um "uso alternativo do essencialismo" - que sublinha a conveniência de a naturalização das funções domésticas e maternas das mulheres ser usada para lhes reconhecer uma vantagem comparativa nas estratégias de pacificação comunitária e de proximidade - torna-se objecto de amplo consenso a centralidade "natural" das mulheres nas respostas a estas formas de conflitualidade que designo por novíssimas guerras. 
res dos homicídios dos seus filhos. De um modo geral, são os afectos e a vontade de actuar como agentes de mudança social que dão força a estas mulheres e as mobilizam.

Apesar de, em cenários de novíssimas guerras, serem os homens (e jovens adolescentes) os principais perpetradores e vítimas da violência armada, as mulheres são profundamente afectadas: são as que ficam com a responsabilidade de apoiar as suas famílias e comunidades e também as vítimas directas da proliferação de armas de fogo. Esta nova violência actua cada vez mais no espaço micro-social, afectando a subjectividade e a inter-subjectividade. Por isso mesmo, as reacções organizadas de repúdio a esta violência, ou os espaços de emergência de novíssimas pazes, têm um carácter mais micro, mais privado, e baseiam-se em argumentos também eles subjectivos, desconstruindo o mito que associa armas de fogo a maior protecção e segurança, e desafiando construções de masculinidade militarizada e violenta que faz equivaler a posse de armas a uma forma de exercício de poder.

A denúncia destes tipos de violência, com maior ênfase na subjectividade, representa um enorme contributo para as propostas de redefinição e de reconhecimento de zonas pouco nítidas, onde a (micro)guerra se dilui num aparente contexto de (macro)paz.

\section{Conclusão}

À semelhança das guerras irregulares e informais da segunda metade do século XX, que não se ajustavam a uma determinada concepção de guerra mas constituíram, no entanto, o prelúdio das novas guerras típicas dos anos 90, está a emergir, agora à margem destas novas guerras, e à escala global, um novo tipo de conflitualidade violenta, que, por não se ajustar a nenhuma das concepções de guerra já existentes, não é ainda considerada prioritária ou relevante.

Estes novos conflitos correspondem a uma dinâmica de disseminação física da violência armada, a uma escala cada vez mais micro, e têm como cenários privilegiados as periferias de grandes centros urbanos. Estas manifestações de novíssimas guerras ocorrem em países que vivem formalmente em paz: seja em sociedades que vivem processos de reconstrução pós-conflito, onde facilmente se opera uma transferência da violência militar anterior para uma violência social disseminada associada ao uso de armas de fogo, seja em situações de hiper-concentração territorial de violência armada em contextos de paz formal e institucionalizada.

Neste novo tipo de conflitualidade, cruzam-se duas dinâmicas de sentido oposto: uma dinâmica "descendente", traduzida na "descida" da violência armada (organizada) cada vez mais ao terreno do doméstico, e uma 
dinâmica "ascendente", de intensificação de formas "tradicionais" de violência suburbana. Por isso mesmo, as novíssimas guerras apresentam traços das novas guerras - ou de conflitos internos que ocorrem maioritariamente em Estados colapsados - e da criminalidade urbana de larga escala, seja quanto às causas, aos actores, aos objectivos ou às estratégias. Os seus objectivos passam pelo controlo do território e de recursos estratégicos, mas não se trata de conflitos territoriais ou por recursos que opõem grupos beligerantes que disputam ao Estado o monopólio do uso da força. São conflitos que têm uma vocação de poder, mas de um poder paralelo, que não pretende substituir-se ao poder estatal. Resultam, entre outros factores, dos elevados índices de desigualdade social, do rápido crescimento das grandes cidades, da disponibilidade crescente de armas de fogo e do aumento do narcotráfico, ou seja, da agudização de violências estruturais acumulados ao logo de décadas.

A dificuldade de delimitação de uma fronteira entre a esfera interna e internacional nestes contextos faz com que a conceptualização e análise das novíssimas guerras dependa das "lentes" com que as interpretamos: se nos centrarmos na dimensão interna veremos apenas um cenário de criminalidade e violência urbana hiper-concentradas, sem quaisquer objectivos políticos; se analisarmos as ligações entre estes fenómenos locais e as redes transnacionais de tráfico de armas e de drogas, e entendermos os impactos destes fenómenos locais no contexto internacional, veremos que estamos perante um fenómeno de tipo novo, que se está a globalizar. Trata-se, portanto, de um localismo globalizado (Santos, 1997), de manifestações de violência armada, de alta intensidade, em micro-territórios urbanos, que emergem e se expandem a nível global.

O Rio de Janeiro constitui um claro exemplo deste novo tipo de conflitualidade: uma mega-metrópole de um país que vive formalmente em paz, mas conta, actualmente, com uma das taxas de homicídios mais elevadas do mundo, directamente associadas à proliferação de armas de fogo e à emergência do narcotráfico na cidade. Os rostos desta violência são masculinos, e cada vez mais jovens. Da mesma forma, são também masculinos e jovens os rostos das principais vítimas.

De facto, o monopólio masculino do uso e posse de armas de fogo é uma expressão da socialização em construções de um tipo de masculinidade, violenta e militarizada, de culturas locais e nacionais em que a utilização masculina de armas de fogo é a norma. E as manifestações desta masculinidade violenta, que fazem equivaler a posse e utilização de armas a uma forma de exercício de poder, constituem uma enorme fonte de ameaça e de insegurança para as mulheres. A exacerbação caricatural da masculi- 
nidade hegemónica e militarizada é o fundo comum que une as culturas de violência presentes em todas as escalas de guerra (as "velhas", as "novas" e as "novíssimas"). Se é lícito ver neste fenómeno uma outra expressão de localismo globalizado (Santos 1997), é também a esse conceito que se reconduzem as práticas de prevenção e de resposta à violência armada organizada localmente ensaiadas. Como contraponto ao perfil de cultura de violência assinalado, estas estratégias de prevenção e de resposta - as "novíssimas pazes" - têm uma articulação forte com as perspectivas feministas.

\section{Referências Bibliográficas}

African Studies Centre; Transnational Institute; NEP/CES; CIP (2003), Failed and Collapsed States in the International System. (http://www.tni.org/reports/ failedstates.pdf).

Amnistia Internacional (2003), "Women in Brazil Take a Stand against Guns" (http:// web.amnesty.org/web/wire.nsf/February2003 print/Brazil).

Aguiar, Thais (2004), "Armas de fogo foram usadas em metade dos homicídios de mulheres no Brasil”, 14/12/2004 (www.desarme.org).

Bandeira, António Rangel, "Congresso Brasileiro aprova proibição de armas", 10/12/ 2003 (www.vivario.org.br/publique/).

Briceño-León, Roberto (2002), "La nueva violencia urbana de América Latina", Sociologias, 8, 34-51.

Collier, Paul; Hoeffler, Anke (2000), "Greed and Grievance in Civil War", World Bank Policy Research Paper 2355. Washington D.C.: World Bank.

Connell, R. W. (1985), "Masculinity, Violence and War", in Paul Patton; Ross Poole, War/Masculinity. Sydney: P. Patton and R. Poole.

Dowdney, Luke (2003), Crianças do tráfico. Rio de Janeiro: 7 Letras.

Duffield, Mark (2001), Global Governance and the New Wars. London: Zed Books.

Dupas, Gilberto (1999), Economia global e exclusão social. Pobreza, emprego, Estado e o futuro do capitalismo. São Paulo: Paz e Terra

Fisas, Vicenç (1998), Cultura de paz y gestión de conflictos. Barcelona/Paris: Icaria/ UNESCO.

Gizewski, Peter; Homer-Dixon, Thomas (1995), "Urban Growth and Violence: Will the Future Resemble the Past?", Occasional Paper, Project on Environment, Population and Security, University of Toronto, 1995 (http://www.library.utoronto. ca/pcs/eps/urban/urban1.htm).

Jackson, R. (1998), "Surrogate Sovereignty? Great Power Responsibility and 'Failed States", Failed States and International Security: Causes, Prospects and Consequences. West Lafayette: Purdue University. 
Kaldor, Mary (1999), New and Old Wars: Organised Violence in a Global Era. Cambridge/ Stanford: Polity Press/Stanford UP.

Kaldor, Mary (2001), Las nuevas guerras. Violencia organizada en la era global. Barcelona: Tusquets Editores.

Kalyvas, Stathis N. (2001), “'New' and 'Old' Civil Wars: A Valid Distinction?”, World Politics, 54(1), 99-118.

Lealdino, María Aparecida (2000), "Violencia urbana en Brasil: tratamiento en la prensa”, Papeles de Cuestiones Internacionales, 71, 91-101.

Manwaring, Max G. (2005), "Street Gangs: The New Urban Insurgency", Strategic Studies Institute, U.S. Army War College, (http://www.carlisle.army.mil/ssi/pdffiles/ PUB597.pdf).

Miall, Hugh; Ramsbotham, Oliver; Woodhouse, Tom (1999), Contemporary Conflict Resolution: The Prevention, Management and Transformation of Deadly Conflicts. Cambridge: Polity Press.

Pettman, Jan Jindy (1996), Worlding Women: A Feminist International Politics. London: Routledge.

Phebo, Luciana; Robim, Michel (2004), "O papel das mulheres na prevenção ao uso de armas de fogo”, 14/12/2004 (www.desarme.org).

PNUD (1994), "Redefining Security: The Human Dimension”, Current History, 94, 218-222.

Pureza, José Manuel; Moura, Tatiana (2004), “O regresso da paz negativa?”, Revista de História das Ideias, 25, 157-168.

Santos, Boaventura de Sousa (1997), "Pluralismo jurídico, escalas y bifurcación”, Conflicto y Contexto. Colômbia: Instituto SER de Investigaciones.

Santos, Boaventura de Sousa (1997), "Quando o local é global e vice-versa”, Estado de São Paulo, 5-1-97.

Spanger, H. (2000), "Failed State or Failed Concept? Objections and Suggestions", Failed States III: Globalisation and the Failed State. Florence: Purdue University (www.ippu.purdue.edu/failed_states/2000/papers/spanger.html).

The Comission on Global Governance (1995), Our Global Neighbourbood. New York: Oxford UP.

Tickner, J. Ann (1992), Gender and International Relations. New York: Columbia UP. Tickner, Ann (2001), Gendering World Politics. Issues and Approaches in the Post-Cold Era. New York: Columbia UP.

Young, J. (1999), The Exclusive Society. London: Sage Publications.

Zaluar, A. (1994), O condomínio do diabo. Rio de Janeiro: Revan.

Zaluar, A.; Noroña, J.; Albuquerque, C. (1994), "Violência: pobreza ou grandeza institucional”, Cadernos de Saúde Pública, 10 (Supl. 1), 213-217. 